\title{
TASK-BASED LEARNING IN THE TEXTBOOK ENGLISH FOR PALESTINE
}

\author{
Rasha Sameer Karaki \\ Al-Quds Open University, Hebron Branch, Palestine \\ E-mail: karaki_2009@hotmail.com \\ Mohammed Abdul Hakim Farrah \\ English Department, Faculty of Arts, Hebron University, Palestine \\ E-mail: mfarrah@hebron.edu
}

APA Citation: Karaki, R., \& Farrah, M. (2019). Task-based learning in the textbook English for Palestine. English Review: Journal of English Education, 8(1), 19-26. doi: 10.25134/erjee.v8i1.2352.

\begin{abstract}
The aim of the study is to examine the ninth grade teachers' perceptions towards task-based learning (TBL) method and analyze the tasks and activities in the textbook of English for Palestine - Ninth Grade. In addition, this study aims at evaluating the appropriateness and the effectiveness of TBL in the classroom. The researcher used four methods to collect data, namely questionnaire, classroom observation, interview, and content-analysis checklist. The sample of the study consisted of 185 teachers (males \& females) from the government and UNRWA schools in Hebron District. The overall findings of the study revealed that the teachers' perceptions towards TBL were positive and highly acceptable; they supported the effectiveness of communicative language teaching (CLT) and TBL in EFL classrooms. Then, the results of observational data showed that some teachers use new communicative methods for teaching language skills while others use the traditional ones. Meanwhile, the results of interviews indicated that the challenges of task-based learning were big-sized classes, length of material, lack of time, and lack of technological tools. The study ended with recommendations for syllabus designers, teachers, and students. It is recommended that the teaching and learning of English language skills at the Palestinian schools should be enhanced by the use of new flexible methods, such as TBL and communicative language teaching.
\end{abstract}

Keywords: evaluation; task-based learning; English for Palestine.

\section{INTRODUCTION}

Communicative language teaching (CLT) emerged as a new approach to language teaching and learning in the 1970 s and 1980s. It is even regarded as a flexible approach to language teaching which is based on the theory that the primary function of language use is communication (Richards \& Rodgers, 2001). This does not mean that this approach does not have limitation as there are others who criticized this approach (Johnson \& Morrow, 1981; Swan, 1985). In the past decades, several scholars in applied linguistics and in the field of second language acquisition (SLA) asserted the significance of communicative activities for teaching language skills in the EFL classroom; the teaching institutions, curriculum designers, researchers, and teachers all around the world started to rethink and plan strategies and language programs within the communicative approach (Fotos \& Ellis, 1991; Harmer 2007; Nunan, 1989; Thompson \& Millington, 2012).

One of the methods that emerged from this approach is TBL (Brown, 2007; Ellis, 2003); it had gained increasing importance all around the world. The early implementation of TBL within the communicative framework for language teaching was Prabhu's (1987) Bangalore project. In this methodology, the students were presented with a task and did not focus on the language rules during the performance; the task was meaning-based and had a non-linguistic outcome. Because of TBL connections with CLT methodology and support from some SLA linguists, it gained considerable attention within applied linguistics. In recent years, a number of researchers, syllabus designers and material developers have called for a shift in language learning and teaching towards this method (Ellis, 2003; Helm, Guth, \& Farrah, 2012; Philp, Adams, \& Iwashita, 2014). TBL is recognized as an effective way for developing students' abilities in English language skills, grammar, and vocabulary. It focuses on the meaning of language rather than its form (Brown, 2007; Ellis, 2003; Krashen, 1982; Nunan, 2004; Thompson \& Millington 2012; Willis, 2007). Skehan (1998) described the task as an activity or a related set of 
strategies that includes the priority of meaning, a problem to solve, and a relationship to real-life tasks, objectives and outcomes. Thus, the priority of TBL is placed on the completion of tasks that are assessed in terms of outcome (Brown, 2007; Willis, 2007).

The use of TBL methodology in the EFL classroom improves students' interaction and motivation within the large classes. A number of studies reported the benefits of TBL. The benefits included better learning attainments, better oral English performance, and better learning motivation (Zhang, 2013). The use of this method also gives students a different way for understanding the language as a tool instead of a specific goal. This is in line with Chalak (2015) who indicated that TBI has positive effects on leaners. Moreover, the use of TBL method facilitates implicit learning and acquisition of language, develops students' knowledge of difficult grammatical rules, and enhances their critical thinking skills (Awad, 2013; Carless, 2002; Fotos \& Ellis, 1991; Ruso, 2007; Thanh \& Huan, 2012; Thompson \& Millington, 2012; Wicking, 2011).

Despite the benefits of TBL, some researchers found that TBL was viewed with some challenges. For example, Burrows (2008) argued that the Japanese collectivist environments minimize the benefits of TBL due to cognitive and socio-cultural differences. In addition, Stroud (2013) and Careless (2002) showed that the rejection of TBL may be attributed to low motivation, non-participation, noise, lack of involvement, large classes, time limits, unqualified teachers and the use of L1. Moreover, Ganta (2013) claimed that the difficulty of task, the familiarity with the types of topics, the linguistic deficiency, the learners' needs and desires, the teachers' perceptions, and the issues of language expansion and correctness influence the TBL use in the classroom. Similarly, Dickinson (2010) claimed that the students' expectations and styles as well as the affective dimensions, such as the culture background and geographical, demographic, and socio-cultural similarities may affect students' participation and interaction during TBL.

Yet, TBL has a crucial role in enhancing the process of teaching and learning language skills. Although it is significant and has been in practice for several decades, little research exists that has examined its appropriateness in the textbooks. In this case, several studies reported that the textbook is an essential component in the educational process (Hutchinson \& Torres, 1994; Richards, 2001; Sheldon, 1988). In the same vein, Cunnigsworth (1995) considers textbooks as effective sources for self-direction, ideas and activities, and an aid for novice teachers who are in their way to gain confidence. Moreover, Harmer (2007) considers that the most vital element in textbooks is the ability of the teachers to engage learners with the content they are going to be dealing with.

Textbook evaluation is an educational requirement since it displays how a textbook can be developed. A variety of definitions for evaluation have been used in the field of applied linguistics. Brown and Rodgers (2002, p. 289) define evaluation as "the process of seeking to establish the value of something for some purpose." According to Brown (1989, p. 223), evaluation "is a systematic collection and analysis of all relevant information necessary to promote the improvement of the curriculum, and assess its effectiveness and efficiency as well as the participants' attitudes within a context of particular institutions involved." Sheldon (1988) added that the textbook evaluation consists of constructing criteria; the criteria and the key questions are basic elements for setting up the material evaluation scheme. Long (2015) deemed there is a need to initiate a needs analysis in order to determine learners' authentic needs before preparing a task-based. Thus, it is a cyclical approach where needs are identified before preparing any textbooks, but then there is a need to evaluate and analyze the content of the textbook to examine whether the textbooks are achieving their objectives.

According to the researchers' view, textbook evaluation is an essential factor for understanding and comprehending the textbooks' content, style, and objectives which suit the learners' needs. Accordingly, this study aims to examine the ninth grade teachers' perceptions towards TBL and analyze the tasks and activities in the textbook, English for Palestine -Ninth Grade (9A \& 9B). The textbook English for Palestine - Ninth Grade introduces a number of communicative activities and tasks with the objective of improving students' abilities to learn the language skills communicatively. However, it is not known to what extent the tasks and activities in the textbook are appropriate and effective. Therefore, this study is the first one which aims to investigate the ninth grade teachers' perceptions towards TBL and evaluate and analyze the tasks and activities in the textbook. 
ENGLISH REVIEW: Journal of English Education

Volume 8, Issue 1, December 2019
p-ISSN 2301-7554, e-ISSN 2541-3643

https://journal.uniku.ac.id/index.php/ERJEE

\section{METHOD}

A descriptive method was adopted for carrying out the study due to its relevance for examining teachers' perceptions towards TBL and investigating its appropriateness in the textbook as well as its effectiveness in the classroom. The population of the study included all English teachers for Ninth Grade at the government and UNRWA schools in Hebron District. Questionnaires were distributed through the Directorate of Education in Hebron to schools. 180 English teachers consisting of 76 male and 109 female filled in the questionnaires. The 180 English teachers come from the government (162) and UNRWA (23) schools in Hebron District. The study used questionnaire, classroom observation, interview, and content-analysis checklist to collect data.

First, a questionnaire was designed and administered in the second semester of the academic year 2014-2015. The questionnaire consisting of 68 items was divided into two sections; demographic data and teachers' perceptions towards TBL. Its main purpose was to examine teachers' understanding of TBL concepts and to investigate their perceptions towards the tasks in the textbook as well as the tasks that they use. The reliability of the questionnaire was calculated by the Cronbach Alpha formula. The results indicated that the reliability of the questionnaire $(0.91)$ indicating that the instrument is suitable for conducting such a study.

Second, according to several researchers (Cunningsworth, 1995; McGrath, 2002; Miekley, 2005; Mukundan \& Nimehchisalem, 2012), the checklist approach has the advantage of providing comprehensive and systematic way to determine that all relevant elements are available. In order to build appropriate criteria for evaluating TBL, the researchers reviewed different sources, such as Akef (2011), Ali (2010), Awad (2013), Ellis (2003), Grainger (2002), Mukundan and Nimehchisalem (2012), McGrath, 2002, and Willis, (2007), Miekley (2005). The most related items from these articles extracted, modified, and added by the researchers, and other referees. The researchers discussed the general criteria items that are mentioned in the checklist for evaluating TBL. The following criteria are emphasized in several studies; Authenticity, Motivation, Variety in the Topics of Tasks, Variety in Types of Tasks, The Gradation of Tasks, Stages of Task, Language Background Knowledge, Cultural
Background Knowledge, and Text Visuals. A checklist was constructed after reviewing different resources (Akef, 2011; Awad, 2013; Berardo, 2006; Cunningsworth, 1995; McGrath, 2002; Miekley, 2005; Mukundan \& Nimehchisalem, 2012; Sheldon, 1988) for collecting and analyzing the information regarding the content of tasks and activities in the light of the suggested criteria. These criteria might be a clue to determine the main areas of strengths and weaknesses in tasks and activities. The checklist consisted of 20-item which included the most important characteristics of TBL. Its main purpose was to identify to what extent the tasks and activities in Pupil's Book (9A \& 9B) of English for Palestine - Ninth Grade match the suggested criteria for evaluating TBL.

Third, fifteen visits were conducted by the researchers for observing classes of $9^{\text {th }}$ grade from the government and UNRWA schools in Hebron city in the second semester of the academic year 2014-2015. An audio recording, notes, and an observation sheet were used for observing classes and collecting the needed information. Its main purpose was to validate the teachers' perceptions towards TBL by comparing whether what they indicated in the questionnaire was consistent with what they did in their classrooms.

Last, Structured interviews were carried out with 15 teachers of the ninth grade; two English language supervisors from the directorate of education and 13 English teachers; 3 males and 10 females from the government and UNRWA schools in Hebron city. They were asked four questions based on the research questions of the study. This method was used as a follow up to the questionnaire and classroom observation. Its main purpose was to discover teachers' perceptions about TBL.

\section{RESULTS AND DISCUSSION}

This section presents the results and discussion of the study. The information used in this study was collected through distributing a questionnaire, classroom observation, interviews, and a content analysis checklist. Frequencies, percentages, means, and standard deviations were used to indicate and clarify the final collected data of the study.

\section{Teachers' general perception towards TBL}

To analyze teachers' general perception towards TBL, descriptive statistics (means and standard 
deviations) were calculated for the questionnaire and their standard deviation. items. Table 1 shows the calculated mean of items

Table 1. Means and standard deviations for teachers' general perception towards Task-Based Learning (TBL)

\begin{tabular}{clcc}
\hline \multicolumn{1}{c}{ Item } & M. & SDs. \\
\hline 1 & provide a relaxed classroom atmosphere. & 3.13 & 0.70 \\
11 & promote communicative competence. & 3.12 & 0.60 \\
5 & integrate all language skills. & 3.12 & 0.69 \\
13 & enable learners to participate in the different language functions. & 3.12 & 0.62 \\
9 & suit both learners and teachers. & 3.11 & 0.66 \\
16 & improve learners' interaction skills. & 3.09 & 0.64 \\
18 & support a collaborative learning. & 3.09 & 0.62 \\
7 & enhance students' creative thinking. & 3.08 & 0.58 \\
15 & enhance self-learning. & 3.07 & 0.60 \\
2 & promote the actual use of target language. & 3.07 & 0.58 \\
4 & meet the learners' needs and interests. & 3.06 & 0.66 \\
6 & require much preparation time compared with other approaches. & 3.05 & 0.71 \\
8 & promote critical thinking. & 3.02 & 0.66 \\
14 & enable learners to manipulate different features of the language. & 3.01 & 0.66 \\
19 & allow learners to rehearse different real life skills. & 3.01 & 0.66 \\
12 & encourage student-centered activities. & 2.99 & 0.59 \\
17 & enhances learners' intrinsic motivation. & 2.99 & 0.59 \\
3 & suit all students' levels. & 2.88 & 0.82 \\
10 & don't overlook the role of grammar in performing a task. & 2.75 & 0.72 \\
\hline
\end{tabular}

Table 1 indicates that the teachers' perceptions towards the concepts of TBL are generally positive and highly acceptable. They agreed with the effectiveness of using new communicative methods in the classroom. This comes in line with Vazquez, Molina, and Lpoez (2015) and Thanh and Huan (2012) who emphasized the effectiveness of TBL in promoting students' motivation for learning the language. The results of this table indicate that some tasks do not suit all students' styles and expectations. This is consistent with Burrows (2008) who pointed out that the classrooms do not always go with students' expectations and teaching methodology due to various teacher- student beliefs and ideas. Additionally, the results indicate that the allocated time for applying TBL is insufficient. The teachers believe that tasks are time-consuming and need a long time to prepare.

Teachers' perception towards TBL activities in English for Palestine - Ninth Grade

To answer this question, descriptive statistics (means and standard deviations) were calculated for the questionnaire items that are related to teachers' perception towards task-based learning (TBL) activities in English for Palestine - Ninth Grade. Table 2 shows the calculated mean of items and their standard deviation.

Table 2. Means and standard deviations for teachers' perceptions towards the tasks in the Textbook English for Palestine - Ninth Grade

\begin{tabular}{|c|c|c|c|}
\hline & Item & M. & SDs. \\
\hline 1. & The tasks provide opportunities for collaborative activities among learners. & 3.09 & 0.63 \\
\hline 2. & There is a variety of meaningful activities. & 3.06 & 0.65 \\
\hline 3. & Some tasks are difficult for most of the students to deal with in language skills. & 2.97 & 0.80 \\
\hline 4. & Speaking tasks and activities motivate students to talk about their concerns and interests. & 2.96 & 0.67 \\
\hline 5. & The tasks make comprehension easier in reading & 2.94 & 0.66 \\
\hline 6. & The tasks are relevant to our culture. & 2.94 & 0.74 \\
\hline 7. & The tasks are related to the learners' needs and interests. & 2.92 & 0.69 \\
\hline 8. & The tasks are clear and specific. & 2.91 & 0.67 \\
\hline 9. & The tasks help to increase student's talking time & 2.90 & 0.66 \\
\hline 10. & The tasks help encourage critical thinking. & 2.89 & 0.74 \\
\hline & The tasks used help build students' confidence. & 2.89 & 0.63 \\
\hline 12. & There is balance in the presence of TBL for the main skills, listening, speaking, reading & 2.88 & 0.66 \\
\hline
\end{tabular}


and writing.

13. The tasks enhance free learning opportunities in writing

$2.84 \quad 0.77$

14. There are themes that encourage communication outside classroom. $r .83$

15. The tasks meet the individual differences among students. $\quad 2.82 \quad 0.72$

16. The tasks are suitable to the students' level. $\quad 2.70 \quad 0.80$

17. The time for learning is sufficient $\quad 2.42 \quad 0.92$

Table 2 shows that the teachers' perceptions towards the tasks in the textbook are positive and highly acceptable. With regard to the objectives of the textbook, the results indicate that the objectives of the textbook are appropriate and go with the desires of the targeted students where the means are between $2.94-2.81$. The clarity of objectives in the textbook facilitates the teaching and learning process. This is in line with Al-Amri (2008) who emphasized that the objectives of the textbook should be explicit and the degree to which it satisfies them should be measurable.

Concerning the content of the textbook, the results indicate that the textbook has a variety of meaningful communicative activities from the real life that focus on learning language skills cooperatively, where the means are between $3.9-$ 2.42. This is consistent with Bahrami (2013), Ruso (2007), Robinson (2011) and Burrows (2008) who asserted the effectiveness TBL method; they manipulated that the tasks provide a context for negotiating the meaning of language and opportunities for collaborative learning. The results also indicate that the allocated time for applying TBL is insufficient. The researchers attribute this to the long material, the difficulty of tasks, the large classes, and the limited time. This is in line with Willis (2007) and Carless (2002) who pointed out that the time for preparation and the length of material may affect the adoption of task- based learning as a methodology in the EFL classroom.

First, the results of observational data indicated that three teachers out of 15 implemented TBL method in their classes despite its challenges, such as overcrowded classes and limited time. The students were involved and engaged during doing the tasks in groups. This agrees with Vazquez, Molina, and Lpoez (2015) who state the students prefer to work in pairs or in groups; this may lead to the greater use of L2 as well as to the improvement of their linguistic skills. The researchers believe that working in pairs or in groups may relieve students' anxiety and develop students' interaction and rapport. This is in line with Willis (1981, p. 188, as cited in Ruso, 2007) who recommended a good friendly interaction between teacher and students as rapport; she states "when there is rapport, it becomes enjoyable for students and the teacher to study together."

In addition, the results showed that just two teachers out of 15 implemented TBL used technology. The researchers believe that the use of technological tools for applying tasks in the classroom attracts students' attention and motivates them to learn and practice language skills for communication. This is in line with Shehadeh and Coombe (2012) who pointed out that the technology, such as internet, video recording, music, and songs can enhance TBL classroom context and facilitate L2 teaching and learning.

The results of classroom observations also revealed that ten teachers out of 15 did not use TBL method in the classroom. Although the textbook includes a lot of tasks and activities, such as pair work and group work activities, the teachers do not engage students in such interactive tasks. This indicated that some teachers usually use traditional methods for teaching language skills due to the lack of time, overcrowded classes, and the lack of educational and training programs. The results also indicated that some classes were teacher-centered; the students were just receivers of L2 knowledge due to their reluctance and shyness for speaking out.

With regard to the use of $\mathrm{L} 1$, the results showed that some teachers mixed between L1 and L2 for explaining the rules and the steps of task due to students' anxiety of using L2. This is consistent with Swain and Lapkin (2000) who studied a group of Hungarian and French students and found that they frequently use their mother tongue during communicative tasks; the students may use L1 if they are not able to carry out the task in English. The researchers think that the use of mother tongue by students is a challenging issue as well as is one of the teachers' concerns. This in line with Carless and Gordan (1997) and Carless (2004) who pointed out that the Hong Kong primary students use L1 during tasks and teachers; they attributed this as a major difficulty in using TBLT.

Second, the results of interviews indicated that just the task which are included at the end of 
each unit integrate the language skills. The researchers believe that all tasks which are included in the textbook should integrate language skills in order to improve students' abilities for communication inside and outside the classroom. They also indicated that some tasks are difficult, complex, and confusing for both students and teachers. With regard to the relevance of tasks with the culture, all 15 teachers said that "the tasks are relevant to our culture." One of the teachers said that "the tasks are relevant not only to our Palestinian culture or Arab-Islamic culture, but also they are relevant to the international culture." This result is positive and indicates the relevance of the material to students' culture may facilitate the learning of language skills.

Moreover, the results indicated that the majority of teachers prefer working in pairs or in groups because more ideas and more views will be presented during doing the task or activity. They believe that the work in groups encourages students to express their ideas and speak aloud without any feeling of stress or shyness. Some teachers said that "individual work is better than group work because working in groups may make noise as well as may affect the classroom management during doing the task." The researchers think that the teachers preferred the individual work due to the difficulty of some topics of tasks in the textbook; they believe that the individual work may avoid the noise or indiscipline in the classroom. One of the teachers said that task-based activities promote the learning of English language just when we have ideal situations for teaching. The teacher believes that the implementation of TBL approach inside the classroom is a burden for teachers and students owing to the length of new material and large classes.

Concerning the teachers' suggestions, the results indicated that the majority of teachers suggested that the allocated time should be sufficient for applying tasks. Moreover, the material should be shorter, varied, and easier. The results also indicated that 7 teachers out of 15 suggested the use of technology for applying TBL; using it attracts students' attention and motivates them to practice L2 and learn the language skills.

Lastly, the results of the content-analysis revealed that the textbook is rich in tasks and activities which enhance the learning of language skills. Regarding the number of items per task, the results indicated that the items and ideas of tasks are not distributed appropriately. Some tasks have four or five items while others have more than five. The researchers think that the distribution of tasks' items should be appropriate and balanced in order to facilitate the implementation of TBL in the classroom.

The results indicated that some tasks are graded appropriately, authentic, interesting, clear, and understandable while some are not. They also indicated that some tasks in the textbook do not suit all students' needs and levels. In addition, the results of the content analysis indicated that all tasks in the textbook have appropriate and clear objectives and outcomes and introduce students to a variety of topics. They have also colorful and authentic artworks and graphs except the tasks in unit three. Moreover, they indicated that some tasks are meaningful and aim to develop communicative language skills and enhance creative and critical thinking while some tasks do not have any communicative purpose and just focus on linguistic forms and rules. Additionally, they indicated that not all included tasks integrate the language skills; they focus on one or two skills. The results showed that some tasks in the textbook are culture-specific while some are not.

These results revealed that the textbook is rich in tasks and activities which enhance the learning of language skills, but the distribution of tasks' items is inappropriate; some tasks have four or five items, while others have more than five. The researchers think that the distribution of tasks' items should be appropriate and balanced in order to facilitate the implementation of TBL in the classroom. According to the researchers, all tasks in the textbook should be varied, graded appropriately, authentic, interesting, clear and understandable, and should suit both students' abilities and teachers' qualifications. The researchers believe that the meaningful and communicative authentic tasks and activities will attract students' attention, enhance their critical and creative thinking skills, and motivate them to learn the language rules effectively. Concerning the relevance of tasks to our culture, the researchers believe that the tasks should not talk about a specific culture or about contradicting beliefs and ideas in the ninth grade or previous grades because at this age this may cause difficulty and confusion for students while doing the tasks; the relevance of authentic tasks to students' religion and culture will enhance their learning of language and add more new information to their knowledge. Certain 
contradicting beliefs could be introduced at more advanced grades.

\section{CONCLUSION}

The aim of this study was to investigate the ninth grade teachers' perceptions towards TBL. The aim also was to examine the appropriateness of tasks and activities in the textbook English for Palestine - Ninth Grade as well as their effectiveness inside the classroom. The overall results indicated that the teachers' perceptions in the questionnaire were not consistent with what they did in the classrooms. The observational data, interviews, and the checklist refuted some teachers' perceptions towards the TBL. In fact, the majority of teachers agreed with the effectiveness and appropriateness of TBL and communicative activities, but in reality not all of them preferred the implementation of such communicative and flexible methods due to different styles and expectations, large classes, noise, bad classroom atmosphere, inadequate time, long material, and lack in workshops and training courses about EFL language teaching and learning and using new communicative methodologies.

The main weaknesses of TBL in the textbook as well as in the classroom in terms of suggested criteria are: 1) The textbook includes a lot of role play tasks; 2) Some tasks in the textbook are not authentic; 3) Some tasks are not related to the Palestinian culture; 4) Some tasks in the textbook do not aim to develop critical thinking skills; 5) Some tasks are not graded appropriately; 6) The extensive language skills activities are not included in the textbook; 7) Some tasks are difficult and ambiguous; 8) Some tasks do not suit both teachers and students; and 9) The use of traditional methods instead of using communicative CLT and TBL.

The researchers attribute these weaknesses to: 1) The material developers and the syllabus designers are not aware of the significance of TBL characteristics and its suitability to students' needs and interests; 2) The syllabus designers are not aware of tasks' authenticity and their relevance to students' culture; 3 ) Designing tasks and activities which aim to develop students' creative and critical thinking skills need much effort and time as well as high proficient and qualified designers; 4) The length of material and the large classes affect the preparation and implementation of tasks and activities in the classroom; 5) The allocated time for doing tasks inside the classroom is insufficient; and 6) The students' levels, the teachers' experience, and the classroom atmosphere also affect the adoption of the TBL methodology.

Based on the findings, the researchers present some recommendations for syllabus designers, Ministry of Education, teachers, and students as follows. First, the syllabus designers should simplify the material. In fact, the material is too long, it has a lot of activities and it needs a long time for preparation. Additionally, they should change the difficult tasks and replace them with varied tasks which suit students' abilities. The Ministry of Education should hold more workshops and training programs about TBL as well as EFL classroom management. This will enhance teachers' proficiency and qualify them to use flexible and communicative methods which work with students' needs. Second, the teachers should prepare enrichment materials with more varied tasks and encourage students to work in pairs or in groups. This will motivate them to speak aloud and enhance their critical thinking skills. Last, the students should revise the basic grammatical rules and vocabulary of language to promote their practice of language skills.

\section{REFERENCES}

Akef, H. (2011). Evaluating the English textbook "Iraq Opportunities" Book 6 for the $2^{\text {nd }}$ intermediate stage. Faculty of Arts, University of Baghdad.

Al-Amri, A. (2008). An evaluation of the sixth grade English language for Saudi Boys' Schools. Master's Thesis. King Saudi University, Saudi Arabia.

Ali, N. (2010). An evaluation of the reading texts and activities in $S B$ and $W B$ of English for Palestine Grade 9. MA Thesis. Islamic University of Gaza, Palestine.

Awad, R. A. (2013). Evaluating English for Palestine 12 in terms of the EFL/ ESL textbook evaluating checklist from the teachers' perspectives in Nablus Directorate Schools. An-Najah Univ. J. Res. (Humanities), 27(11), 2401-2432.

Bahrami, M. (2013). Learning relative clauses by Iranian EFL Learners: Task-based activities versus teacher-focused activities. Mediterranean Journal of Social Sciences, 4(4), 83-90.

Berardo, S. A. (2006). The use of authentic materials in the teaching of reading. The Reading Matrix, 6(2), 60-69.

Brown, J. D. (1989). Language program evaluation: A synthesis of existing possibilities. In R. K. Johnson (Eds.), The second language curriculum (pp. 222-241). Cambridge: Cambridge University Press.

Brown, H. D. (2007). Teaching by principles: An interactive approach to language pedagogy. 
Englewood Cliffs, New Jersey: Prentice Hall Regents.

Burrows, C. (2008). Socio-cultural barriers facing TBL in Japan. The Language Teacher Journal, 32(8), 15-19.

Carless, D. (2002). Implementing task-based learning. ELT Journal, 56(4), 389-396.

Carless, D. (2004). Issues in teachers' reinterpretation of a task-based innovation in primary schools. TESOL Quarterly, 38, 639-662.

Carless, D., \& Gordon, A. (1997). Primary English teachers' attitudes towards the implementation of task-based teaching. Journal of Basic Education, 7, 139-159.

Chalak, A. (2015). The effect of task-based instruction on reading comprehension of Iranian EFL learners. Applied research English language Journal, 4(7), 19-30.

Cunningsworth, A. (1995). Choosing your coursebook. Oxford: Macmillan Heinemann.

Dickinson, P. (2010). Implementing task-based language teaching in a Japanese EFL context. Centre for English Language Studies Postgraduate Programmes. The University of Birmingham, UK.

Ellis, R. (2003). Task-based language learning and teaching. Oxford: Oxford University Press.

Fotos, S., \& Ellis, R. (1991). Communicating about grammar: A task- based approach. TESOL Quarterly Journal, 25, 605-628.

Ganta, T. G. (2015). The strengths and weaknesses of task-based learning (TBL). Scholarly Research Journal for Interdisciplinary Studies, 3(16), 27602771.

Harmer, J. (2007). How to teach English. London \& New York: Longman Inc.

Helm, F., Guth, S., \& Farrah, M. (2012). Promoting dialogue or hegemonic practice: Power issues in telecollaboration. Language Learning \& Technology, 16(2), 103-127.

Hutchinson, T., \& Torres, E. (1994). The textbook as agent of change. ELT Journal, 48(4), 315-328.

Johnson, K., Morrow, K. (1981). Communication in the Classroom. Harlow: Longman.

Krashen, S. (1982). Principles and practice in second language acquisition. New York: Pergamon.

Long, M. H. (2015). Second language acquisition and task-based language teaching. West Sussex, UK: Wiley Blackwell.

McGrath, I. (2002). Materials evaluation and design for language teaching. Edinburgh: Edinburgh University Press.

Miekley, J. (2005). ESL textbook evaluation checklist. The Reading Matrix, 5(2).

Mukundan, J., \& Nimehchisalem, V. (2012). Evaluative criteria of an English language textbook evaluation checklist. Journal of Language Teaching and Research, 3(6), 11281134.
Nunan, D. (1989). Designing tasks for the communicative classroom. Cambridge: Cambridge University Press.

Nunan, D. (2004). Task-based language teaching. Cambridge: Cambridge University Press.

Philp, J., Adams, R., \& Iwashita, N. (2014). Peer interaction and second language learning. New York, NY: Routledge.

Prabhu, N. (1987). Second language pedagogy. Oxford: Oxford University Press.

Richards, J., \& Rodgers, T. (2001). Approaches and methods in language teaching ( $\left.2^{\text {nd }} \quad e d.\right)$. Cambridge: Cambridge University Press.

Robinson, P. (2011). Task-based learning: A review of issue. Language Learning Research Club, 61, 136.

Ruso, N. (2007). The influence of task based learning on EFL classrooms. Asian EFL Journal, 18, 1-23.

Skehan, P. (1998). A cognitive approach to language learning. Oxford: Oxford University Press.

Sheldon, L. (1988). Evaluating EFL textbooks and materials. ELT Journal, 42(4), 237-246.

Stroud, R. (2013). Task-based learning challenges in high schools: What makes students accept or reject tasks? The Language Teacher, 37(2), 21-28.

Swan, M. (1985). A critical look at the communicative approach. ELT Journal, 39(2), 76-87.

Swain, M., \& Lapkin, S. (2000). Task-based second language learning: The uses of the first language. Language Teaching Research Journal, 4, 251-274.

Thanh, L., \& Huan, N. (2012). Task-based language learning and student motivation in vocabulary acquisition. Language Education in Asia Journal, 3(1), 106-120.

Thompson, C., \& Millington, N. (2012). Task-based learning for communication and grammar use. Language Education in Asia Journal, 3(2), 159167.

Vazquez, V., Molina, M., \& Lpoez, F. (2015). Perceptions of teachers and students of the promotion of interaction through task-based activities in CLIL. Porta Linguarum, 23.

Wicking, P. (2011). TBLT in Japan: Task-based language teaching and its effective implementation in the Japanese university classroom. CEU Journal, 3(3), 248-258.

Willis, J. (1981). Teaching English through English. London: Longman.

Willis, J. (2007). Brain-based teaching strategies for improving students' memory, learning, and test taking success. Journal of the Association for Childhood Education International, 83(5), 310315.

Zhang, X. (2013). A case study of exploring viability of task-based instruction on college English teaching in big-sized class. Journal of Language Teaching and Research, 4(4) 693-699. 